\title{
Additional Value of Early Repolarization Pattern in Prediction of Obstructive Coronary Artery Disease as Assessed by Coronary Angiography
}

\author{
Wei-Yi Mei, ${ }^{1} * \mathrm{MD}$, Li-Juan Liu, ${ }^{1} * \mathrm{MD}$, Qing Xu, ${ }^{1} * \mathrm{MD}$, \\ Dong-Dan Zheng, ${ }^{1} \mathrm{MD}$ and Yun-Jiu Cheng, ${ }^{1} \mathrm{MD}$
}

\begin{abstract}
Summary
Recent reports show that an early repolarization pattern (ERP) is associated with a higher incidence of sudden cardiac death in patients with obstructive coronary artery disease (CAD). Sporadic case studies have pointed out that ERP might be related to obstructive CAD.

In consecutive patients who had undergone coronary angiography, we investigated the relationship between ERP and obstructive CAD by evaluating its association with coronary artery stenosis.

The study population consisted of 3785 patients $(59.9 \%$ men; mean age 63.1 years) with or without obstructive CAD. Adjusting for major cardiovascular risk factors, ERP was significantly associated with obstructive CAD (adjusted odds ratio (OR): 2.24 [95\% CI 1.70-2.95]) with an incremental predictive value (ROC AUC 0.76 versus $0.71, P=0.02$; NRI $55.3 \%, P<0.001$; IDI $=0.05, P=0.008)$, specifically in subjects with low risk and intermediate risk. ERP also significantly improved the predictive value for multi-vessel disease (AUC: 0.77 versus $0.72, P=0.02$ for two-vessel disease; 0.79 versus $0.73, P=0.04$ for three-vessel disease). ERP was consistently associated with stenoses of 3 main coronary arteries.

ERP is associated with significant increased risk for obstructive CAD.Further studies are warranted to confirm our results and to elucidate the specific pathogenic mechanisms.
\end{abstract}

(Int Heart J 2019; 60: 296-302)

Key words: Ischemic heart disease, J-point elevation, Risk factors

$\Lambda$ n early repolarization pattern (ERP) is defined as a J-point elevation from the baseline $(0.1 \mathrm{mV})$ and or a notching or slurring morphology of the QRS complex in at least 2 contiguous leads on a standard 12-lead electrocardiogram (ECG). ${ }^{1)}$ ERP has commonly been regarded as a benign finding because it is mostly observed in young, healthy individuals or athletes without structural heart disease. ${ }^{2)}$ However, recent large cohort studies and meta-analysis demonstrated an association between ERP and fatal arrhythmias or sudden cardiac death in patients without structural heart disease. ${ }^{3.8)}$ In addition, other observational studies reported that ERP was related to ventricular fibrillation and sudden cardiac death in patients with obstructive coronary artery disease (CAD). ${ }^{9-11)}$

Obstructive CAD is the leading cause of mortality and morbidity worldwide. Several risk prediction methods have been developed to estimate the probability of a CAD event based on traditional risk factors, such as the Framingham risk score and QRISK. ${ }^{12,13)}$ In spite of this, a siz- able proportion of CAD events occur in individuals who are classified as having low or intermediate risk. ${ }^{14)}$ This calls for the need to improve its risk prediction accuracy. Recently, several case reports have described an augmentation of $\mathrm{J}$ point by myocardial ischemia and our previous prospective cohort study also reported positive risk of ERP associated with CHD mortality. ${ }^{7,15}$ This raises the possibility that ERP might be associated with obstructive CAD. In this study, we aimed to evaluate the association of ERP with obstructive CAD detected via coronary angiography and whether the inclusion of ERP could improve the prediction accuracy of obstructive CAD.

\section{Methods}

Study population: We retrospectively enrolled Chinese individuals who underwent coronary angiography and 12lead resting ECG at the First Affiliated Hospital of Sun Yat-Sen University in Guangzhou, China from March

From the ${ }^{1}$ Department of Cardiology, the Eastern Hospital of the First Affiliated Hospital, Sun Yat-Sen University, Guangzhou, China.

*These authors contributed equally to this work.

This study was supported by grants from the National Natural Scientific Foundation of China (81600260), Guangdong Natural Science Foundation (2016A 030313210), the project of Guangdong Province Science and Technology Plan (2017A020215174), Medical and Health Project of Huangpu District (201607), the project of Kelin new star of the First Affiliated Hospital of Sun Yat-Sen University (Y50186), and the Fundamental Research Funds for the Central Universities in Sun Yat-Sen University (18ykpy08) to Dr. Cheng.

Address for correspondence: Yun-Jiu Cheng, MD or Dong-Dan Zheng, MD, Department of Cardiology, the Eastern Hospital of the First Affiliated Hospital, Sun Yat-Sen University, Guangzhou 510700, China. E-mail: cheng831011@sina.com or 18902300878@163.com

Received for publication July 9, 2018. Revised and accepted August 31, 2018.

Released in advance online on J-STAGE February 22, 2019.

doi: 10.1536/ihj.18-416

All rights reserved by the International Heart Journal Association. 
2013 to December 2016. For the present analysis, we excluded 23 subjectsfor whom J-point amplitude data were missing or incomplete. We also excluded subjects with atrial fibrillation, a pacemaker, bundle branch block, WolfParkinson-White syndrome, idioventricular rhythm, or acute myocardial infarction. The study protocol was approved by the ethics committee of the First Affiliated Hospital of Sun Yat-Sen University, Guangzhou, China.

In addition to undergoing standard resting 12-lead ECG, the subjects provided information regarding their age, gender, smoking/drinking habits, and history of chronic diseases, and received various examinations such as blood pressure, body mass index (BMI), fasting plasma glucose, total cholesterol (TC), triglycerides (TG), lowdensity lipoprotein cholesterol (LDL-C), and high-density lipoprotein cholesterol (HDL-C). Hypertension was defined as history of hypertension or blood pressure $\geq 140$ / $90 \mathrm{mmHg}$. Diabetes was defined as history of diabetes, fasting blood glucose $\geq 126 \mathrm{mg} / \mathrm{dL}$ or any blood glucose $\geq 200 \mathrm{mg} / \mathrm{dL}$ or 2 -hour blood glucose $\geq 200 \mathrm{mg} / \mathrm{dL}$ in the $75 \mathrm{~g}$ glucose tolerance test. Hyperlipidemia was defined as history of hyperlipidemia, total cholesterol $\geq 220 \mathrm{mg} /$ $\mathrm{dL}$ or low-density lipoprotein cholesterol $\geq 140 \mathrm{mg} / \mathrm{dL}$ or triglycerides $\geq 150 \mathrm{mg} / \mathrm{dL}$. The Framingham risk score (FRS) was calculated, and risk groups were categorized into low $(<10 \%)$, intermediate $(10-20 \%)$, or high $(\geq$ $20 \%){ }^{13)}$

Electrocardiographic analysis: All 12-lead resting ECGs performed prior to coronary angiography were reviewed for analysis. Briefly, an ERP is present if all of the following criteria are met: (1) an end-QRS notch or slur on the final $50 \%$ of the downslope of a prominent R-wave; (2) J-point $\geq 0.1 \mathrm{mV}$ in two or more contiguous leads of the 12-lead ECG, excluding leads V1-V3; and (3) QRS duration $<120 \mathrm{~ms}^{1)}$ In the present study, we also analyzed the amplitude of J-point elevation $(0.10-0.2 \mathrm{mV}$ or $\geq 0.2 \mathrm{mV}$ ), $\mathrm{J}$ wave distribution (inferior and/or lateral leads), J wave morphology (notching or slurring), and STsegment patterns after $\mathrm{J}$ point (rapidly ascending or horizontal/descending). All ECG records were read and analyzed in random order by 3 independent cardiologists who were blinded to the patients' medical conditions.

Coronary angiography: All patients underwent coronary angiography for evaluation of palpitations, chest pain, preoperative conditions, and malignant ventricular arrhythmia. Coronary arteries were visualized in left and right oblique planes with cranial and caudal angulations. The presence of coronary stenosis was anatomically assessed based on a modified model of the coronary tree with 15 segments. ${ }^{16,17)}$ The stenotic lesions were evaluated and described as the percentage of lumen diameter reduction. Significant or obstructive CAD was primarily defined as stenosis $\geq 50 \%$ in any major epicardial coronary artery, although the other typical definition of obstructive CAD using the alternative cut-off of a stenosis diameter of $\geq 70 \%$ was also tested. ${ }^{16)}$ Obstructive CAD was also classified into single-vessel or multi-vessel (two- and three-vessel) disease.Angiograms were graded by visual inspection by the cath-lab physician performing the diagnostic procedure, who was blinded to all non-invasive data specific to the study.
Statistical analysis: All continuous data are presented as the mean and standard deviation (SD), and categorical data are reported as numbers and percentages in each group. Unpaired t-tests and the chi-square test were performed to compare continuous and categorical variables, respectively. Multivariate logistic regression analysis was conducted to identify the relationship between ERP and obstructive CAD, adjusted for age, sex, body mass index, hypertension, hyperlipidemia, diabetes mellitus, and smoking status. Receiver operating characteristic (ROC) curves were subsequently generated using $\mathrm{CAD}$ as the event. The added value of ERP for CAD diagnosis was evaluated by comparing the areas under the receiver operating characteristics curve (ROC AUC) of the multivariable logistic regression models without ERP and with ERP. ${ }^{18)}$ For reclassification, we computed the integrative discriminative improvement (IDI) and net reclassification improvement (NRI) associated with the addition of ERP to the model. ${ }^{19}$ ) Statistical analysis was performed with SPSS version 20.0 software (SPSS Inc., Chicago, IL, USA). A $P$-value of < 0.05 was considered statistically significant.

\section{Results}

Baseline characteristics: After application of exclusion criteria, we present results for 3785 individuals undergoing coronary angiography, with a male proportion of $59.9 \%$ and a mean age of 63.1 years. In the study population, the overall prevalence of ERP was $21.6 \%, 66.9 \%$ of the patients had hypertension, $25.6 \%$ had hyperlipidemia, $32.6 \%$ had diabetes mellitus, and $34 \%$ were current smokers. Most subjects $(48.0 \%)$ were low in FRS risk, while $28.5 \%$ were intermediate risk and $23.5 \%$ high risk. Table I lists the baseline characteristics of the study population. Individuals with ERP were more often male and current smokers, had a lower BMI, lower blood pressure, and lower TC, LDL-C and TG levels, and had a higher QRS angle than those without ERP. At baseline, mean age and heart rate were not significantly different between subjects with and without ERP. In addition, subjects with palpitations, chest pain, a pre-operative condition, or malignant ventricular arrhythmia were not significantly different between the two groups.

Association between early repolarization pattern and obstructive coronary artery disease: Obstructive CAD was observed in $545(66.7 \%)$ and 1457 (49.9\%) patients in the ERP and no ERP groups $(P<0.001)$, respectively. Compared to those without ERP, subjects with ERP were significantly associated with obstructive CAD (adjusted odds ratio (OR): 2.24 [95\% CI 1.70-2.95]), adjusted for traditional cardiovascular risk factors (Table II). Similar results were achieved for men (aOR: 2.06 [95\% CI 1.512.81]) and women (aOR: 2.33 [95\% CI 1.76-3.08]) when stratified analyses were performed by gender $(P=0.56)$. Other factors associated with CAD included old age, diabetes mellitus, and current smoking. On ROC curve analysis, the model for obstructive CAD had a significantly higher predictive value when ERP was included (AUC: 0.76 [95\% CI 0.73-0.79]) compared to when it was not (AUC: 0.71 [95\% CI 0.68-0.74]; $P=0.02$ ) (Table II; Figure). The reclassification analysis yielded both a signifi- 
Table I. Baseline Subject Characteristics for Overall Sample and by ERP Status

\begin{tabular}{|c|c|c|c|c|}
\hline Subject characteristics & $\begin{array}{c}\text { All Subjects }(n=3785), \\
\text { mean }(\mathrm{SD}) \text { or } \%\end{array}$ & $\begin{array}{l}\text { No ERP }(n=2968), \\
\text { mean }(\mathrm{SD}) \text { or } \%\end{array}$ & $\begin{array}{l}\text { ERP }(n=817), \text { mean } \\
(\mathrm{SD}) \text { or } \%\end{array}$ & $P$ value* \\
\hline Age (years) & $63.1(11.5)$ & $63.1(11.3)$ & $63.0(12.4)$ & 1.00 \\
\hline Male __ $(\%)$ & $2267(59.9)$ & $1733(58.4)$ & $534(65.4)$ & $<0.001$ \\
\hline \multicolumn{5}{|l|}{ Risk factors for vascular events (\%) } \\
\hline Hypertension & $2531(66.9)$ & $1999(67.3)$ & $532(65.1)$ & 0.23 \\
\hline Hyperlipidemia & $968(25.6)$ & $820(27.6)$ & $148(18.1)$ & $<0.001$ \\
\hline Diabetes mellitus & $1235(32.6)$ & $993(33.5)$ & $242(29.7)$ & 0.27 \\
\hline \multicolumn{5}{|l|}{ Blood pressure, $\mathrm{mmHg}$} \\
\hline Systolic & $137.4(24.8)$ & $138.0(25.9)$ & $135.0(19.9)$ & $<0.001$ \\
\hline Diastolic & $79.6(15.2)$ & $80.1(15.9)$ & $77.7(12.2)$ & $<0.001$ \\
\hline Current smoker $(\%)$ & $1287(34.0)$ & $985(33.2)$ & $302(37.0)$ & 0.04 \\
\hline Body mass index, mean (SD) & $24.4(4.2)$ & $24.5(4.3)$ & $24.1(4.0)$ & 0.006 \\
\hline \multicolumn{5}{|l|}{ Laboratory values, mean (SD) } \\
\hline \multicolumn{5}{|l|}{ Cholesterol, mean (SD), mg/dL } \\
\hline Total cholesterol & $187.9(51.3)$ & $190.6(52.4)$ & $178.2(46.0)$ & $<0.001$ \\
\hline Low-density lipoprotein & $118.1(40.5)$ & $120.3(40.8)$ & $110.1(38.2)$ & 0.01 \\
\hline High-density lipoprotein & $40.8(10.2)$ & $40.8(10.2)$ & $40.8(10.1)$ & 0.95 \\
\hline Triglycerides, mean (SD), mg/dL & $161.2(152.1)$ & $164.7(159.3)$ & $148.3(121.6)$ & $<0.001$ \\
\hline \multicolumn{5}{|l|}{ Electrocardiographic findings } \\
\hline Heart rate, bpm & $71.0(14.0)$ & $71.5(13.9)$ & $69.4(14.2)$ & 0.78 \\
\hline PR interval, ms & $166.7(32.1)$ & $166.7(30.2)$ & $166.6(38.4)$ & 1.00 \\
\hline QTc duration, ms & $422.6(30.1)$ & $423.0(30.1)$ & $421.1(30.2)$ & 0.55 \\
\hline QRS duration, ms & $95.1(15.1)$ & $95.2(14.9)$ & $94.7(15.9)$ & 0.99 \\
\hline QRS angle, degrees & $26.1(38.3)$ & $22.8(39.4)$ & $38.2(31.4)$ & $<0.001$ \\
\hline $\begin{array}{l}\text { Left ventricular hypertrophy on } \\
\text { electrocardiogram }(\%)\end{array}$ & $551(14.6)$ & $443(14.9)$ & $108(13.3)$ & 0.22 \\
\hline \multicolumn{5}{|l|}{ FRS risk groups } \\
\hline Low & $1815(48.0)$ & $1394(47.0)$ & $421(51.5)$ & \\
\hline Intermediate & $1079(28.5)$ & $791(26.7)$ & $288(35.3)$ & \\
\hline High & $891(23.5)$ & $783(26.4)$ & $108(13.2)$ & \\
\hline \multicolumn{5}{|l|}{ Reasons for coronary angiography } \\
\hline Palpitations & $792(20.9)$ & $618(20.8)$ & $174(21.3)$ & 0.77 \\
\hline Chest pain & $2583(68.2)$ & $2027(68.3)$ & $556(68.1)$ & 0.90 \\
\hline Malignant ventricular arrhythmia & $331(8.7)$ & $258(8.7)$ & $73(8.9)$ & 0.83 \\
\hline Pre-operative examination & $79(2.1)$ & $65(2.2)$ & $14(1.7)$ & 0.40 \\
\hline
\end{tabular}

*Significance tests for comparisons by $\mathrm{J}$ wave pattern status based on two-sample $t$-test for continuous subject characteristics and Pearson's $\chi^{2}$ test for categorical subject characteristics. 'SI conversion factors: To convert total, LDL, and HDL cholesterol to mmol/ $\mathrm{L}$, multiply by 0.0259 ; triglycerides to $\mathrm{mmol} / \mathrm{L}$, multiply by 0.0113 ; glucose to $\mathrm{mmol} / \mathrm{L}$, multiply by 0.0555 .

Table II. Association and Incremental Predictive Value of ERP with Obstructive CAD

\begin{tabular}{|c|c|c|c|c|c|c|c|}
\hline & $\mathrm{CAD}<50 \%$ & $\mathrm{CAD} \geq 50 \%$ & $\begin{array}{c}\text { Crude OR } \\
(95 \% \text { CI })\end{array}$ & $\begin{array}{l}\text { Adjusted OR } \\
(95 \% \mathrm{CI}) *\end{array}$ & $\begin{array}{c}\text { ROC AUC } \\
\text { (basic model) }\end{array}$ & $\begin{array}{c}\text { ROC AUC } \\
\text { (ERP added) }\end{array}$ & $\begin{array}{c}\text { ROC AUC } \\
P \text {-value }\end{array}$ \\
\hline \multicolumn{8}{|l|}{ All subjects } \\
\hline ERP (-) & 1511 & 1457 & 1 & 1 & & & \\
\hline ERP (+) & 272 & 545 & $2.08(1.77-2.44)$ & $2.24(1.70-2.95)$ & $0.71(0.68-0.74)$ & $0.76(0.73-0.79)$ & 0.02 \\
\hline \multicolumn{8}{|c|}{ FRS low risk } \\
\hline ERP (-) & 825 & 569 & & & & & \\
\hline ERP (+) & 141 & 280 & $2.75(2.19-3.45)$ & $2.88(2.31-3.59)$ & $0.72(0.69-0.75)$ & $0.78(0.75-0.81)$ & 0.006 \\
\hline \multicolumn{8}{|c|}{ FRS intermediate risk } \\
\hline $\operatorname{ERP}(-)$ & 405 & 386 & & & & & \\
\hline ERP (+) & 94 & 194 & $2.17(1.63-2.87)$ & $2.26(1.51-3.38)$ & $0.70(0.67-0.73)$ & $0.75(0.72-0.78)$ & 0.02 \\
\hline \multicolumn{8}{|c|}{ FRS high risk } \\
\hline ERP (-) & 281 & 502 & & & & & \\
\hline $\operatorname{ERP}(+)$ & 37 & 71 & $1.07(0.70-1.64)$ & $1.09(0.73-1.63)$ & $0.68(0.63-0.73)$ & $0.69(0.64-0.74)$ & 0.78 \\
\hline
\end{tabular}

*Multivariate logistic regression analysis adjusted for age, sex, body mass index, hypertension, hyperlipidemia, diabetes mellitus and smoking status. ERP indicates early repolarization; CAD, coronary artery disease; FRS, Framingham risk score; OR, odds ratio; and ROC AUC, area under the receiver operating characteristics curve. 
cant continuous NRI as $55.3 \%$ (95\% CI 27.7-82.9\%; $P<$ $0.001)$ and a statistically significant IDI (IDI $=0.05,95 \%$ CI $0.03-0.07 ; P=0.008)$. Sensitivity analysis by adding ischemic electrocardiogram changes (indicated by ST segment depression) to the traditional risk factors only slightly increased the predictive value of CAD (AUC: 0.74 [95\% CI 0.71-0.77]). However, further addition of ERP could still improve the predictive values (AUC: 0.78 [95\% CI 0.75-0.81]; NRI: 42.7\% [95\% CI 22.3\%-63.1\%]; IDI: 0.03 [95\% CI $0.01 \%-0.05 \%]$ ).

The study population was then divided into subjects at low $(<10 \%)$, intermediate $(10-20 \%)$, and high $(>20 \%)$ FRS. ERP was tested for incremental predictive value for CAD, separately in each FRS category. ERP was significantly associated with CAD in both the low and intermediate FRS categories (aOR: 2.88 [95\% CI 2.31-3.59] forlow risk group; 2.26 [95\% CI 1.51-3.38] forintermediate risk group), but not in the high FRS category. The risk estimate seemed to be higher in subjects with low risk as compared with subjects with intermediate and high risk. In addition, the incremental predictive value of ERP was

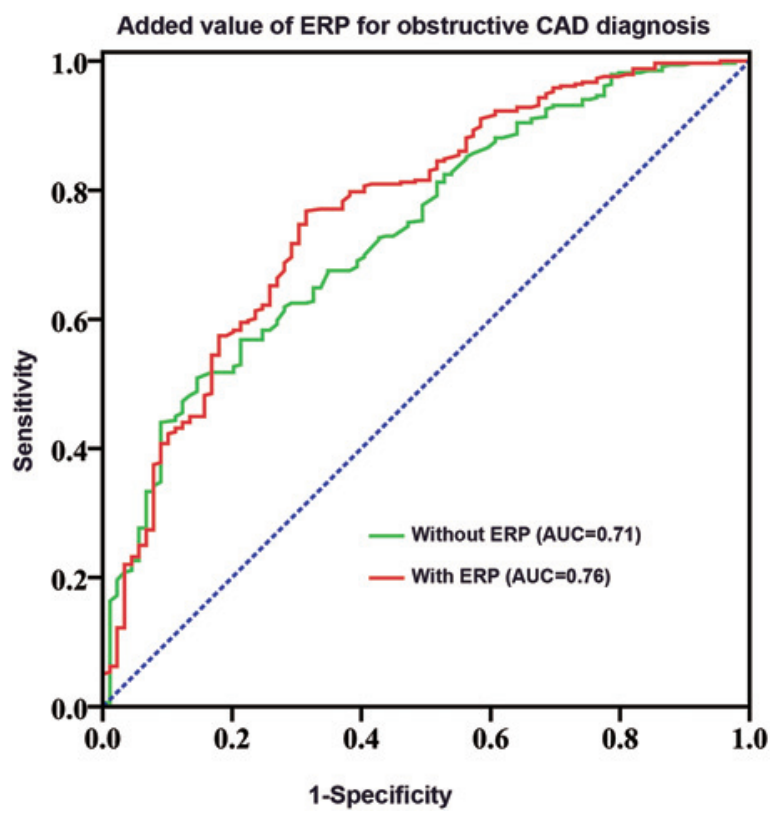

Figure. Comparison of area under the receiver operating characteristic curve (AUC) for obstructive CAD between the full model without and with ERP. ERP indicates early repolarization pattern; and CAD, coronary artery disease. also only significant in the low risk and intermediate risk groups (AUC: 0.78 versus $0.72, P=0.006$ for low risk group; 0.75 versus $0.70, P=0.02$ for high risk group) (Table II).

We further assessed the association between ERP and obstructive CAD according to the severity of coronary stenosis. Interestingly, although ERP remained consistently associated with single-vessel and multi-vessel disease, adding ERP to the fully adjusted model only significantly improved the predictive value for multi-vessel disease (AUC: 0.77 versus $0.72, P=0.02$ for two-vessel disease; 0.79 versus $0.73, P=0.04$ for three-vessel disease). No significant difference could be observed between the discrimination value of ERP for the presence of singlevessel disease. When we used the $>70 \%$ stenosis definition, ERP maintained its significant discrimination incremental value for obstructive CAD (AUC: 0.80 versus $0.72, P=0.03$ ), but the magnitude of the AUC difference seemed to be higher than what was demonstrated with the standard prediction of at least one coronary stenosis > $50 \%$ (AUC difference: 0.08 versus $0.05, P=0.03$ ) (Table III).

Assessment of stenoses of $\mathbf{3}$ main coronary arteries according to early repolarization pattern phenotype: Association of the 3 main coronary arteries with different ERP phenotypes is shown in Table IV. ERP was consistently associated with stenosis of the right coronary artery (aOR: 2.72 [95\% CI 1.36-5.44]), left anterior descending coronary (aOR: 2.31 [95\% CI 1.31-4.07]), and left circumflex coronary (aOR: 2.30 [95\% CI 1.13-4.68]). Of note, compared with subjects with a $\mathrm{J}$ wave amplitude of 0.1-0.19 $\mathrm{mV}$, those with a $\mathrm{J}$ wave amplitude of at least 0.2 $\mathrm{mV}$ experienced higher risk forstenoses of the 3 main coronary arteries. Coronary stenosis was observed in subjects with a $\mathrm{J}$ wave in inferior leads or lateral leads, but not in those with $\mathrm{J}$ waves in both inferior and lateral leads. There was no significant difference in coronary stenosis in subjects with the notching type of ERP as compared with those with the slurring type. Interestingly, ERP with a horizontal or descending ST segment, rather than ERP with a rapidly ascending ST segment, was associated with stenoses of the 3 main coronary arteries.

\section{Discussion}

The present study, involving 3785 individuals undergoing coronary angiography, found a 2-fold increase in the risk of obstructive CAD in subjects with ERP compared with those without ERP, even after adjustment for

Table III. Association Between ERP and Obstructive CAD According to Severity of Coronary Stenosis

\begin{tabular}{lccccccc}
\hline & $\begin{array}{c}\text { No ERP } \\
(n=2464)\end{array}$ & $\begin{array}{c}\text { Any ERP } \\
(n=728)\end{array}$ & $\begin{array}{c}\text { Crude OR } \\
(95 \% \mathrm{CI})\end{array}$ & $\begin{array}{c}\text { Adjusted OR } \\
(95 \% \mathrm{CI}) *\end{array}$ & $\begin{array}{c}\text { ROC AUC } \\
\text { (basic model) }\end{array}$ & $\begin{array}{c}\text { ROC AUC } \\
(\text { ERP added })\end{array}$ & $\begin{array}{c}P \text {-value for } \\
\text { ROC AUC }\end{array}$ \\
\hline Single-vessel disease & 606 & 210 & $1.89(1.27-2.81)$ & $1.92(1.29-2.86)$ & $0.68(0.63-0.73)$ & $0.70(0.65-0.75)$ & 0.58 \\
Two-vessel disease & 410 & 182 & $2.42(1.53-3.83)$ & $2.36(1.47-3.79)$ & $0.72(0.69-0.75)$ & $0.77(0.74-0.80)$ & 0.02 \\
Three-vessel disease & 417 & 154 & $2.01(1.30-3.11)$ & $2.13(1.33-3.41)$ & $0.73(0.69-0.77)$ & $0.79(0.75-0.83)$ & 0.04 \\
CAD $>70 \%$ disease & 951 & 478 & $2.79(2.36-3.31)$ & $2.82(2.44-3.26)$ & $0.72(0.67-0.77)$ & $0.80(0.75-0.85)$ & 0.03 \\
\hline
\end{tabular}

*Multivariate logistic regression analysis adjusted for age, sex, body mass index, hypertension, hyperlipidemia, diabetes mellitus and smoking status. ERP indicates early repolarization; CAD, coronary artery disease; OR, odds ratio; and ROC AUC, area under the receiver operating characteristics curve. 
Table IV. Assessment of Stenoses of Three Main Coronary Arteries According to ERP Phenotype

\begin{tabular}{|c|c|c|c|c|c|c|c|c|c|c|c|c|}
\hline & \multicolumn{3}{|c|}{ Any vessel } & \multicolumn{3}{|c|}{ Right coronary artery } & \multicolumn{3}{|c|}{$\begin{array}{c}\text { Left anterior descending } \\
\text { coronary }\end{array}$} & \multicolumn{3}{|c|}{ Left circumflex coronary } \\
\hline & $\begin{array}{l}\text { No. of } \\
\text { cases }\end{array}$ & $\begin{array}{l}\text { Adjusted OR } \\
(95 \% \mathrm{CI}) *\end{array}$ & $\begin{array}{c}P \\
\text { value }\end{array}$ & $\begin{array}{l}\text { No. of } \\
\text { cases }\end{array}$ & $\begin{array}{c}\text { Adjusted OR } \\
(95 \% \mathrm{CI}) *\end{array}$ & $\begin{array}{c}P \\
\text { value }\end{array}$ & $\begin{array}{l}\text { No. of } \\
\text { cases }\end{array}$ & $\begin{array}{c}\text { Adjusted OR } \\
(95 \% \mathrm{CI}) *\end{array}$ & $\begin{array}{c}P \\
\text { value }\end{array}$ & $\begin{array}{l}\text { No. of } \\
\text { cases }\end{array}$ & $\begin{array}{c}\text { Adjusted OR } \\
(95 \% \mathrm{CI}) *\end{array}$ & $\begin{array}{c}P \\
\text { value }\end{array}$ \\
\hline No ERP $(n=2464)$ & 1457 & & & 817 & & & 1257 & & & 648 & & \\
\hline $\begin{array}{l}\text { Any ERP pattern } \\
(n=728)\end{array}$ & 545 & $\begin{array}{c}2.24 \\
(1.90-2.64)\end{array}$ & 0.004 & 311 & $\begin{array}{c}2.72 \\
(1.36-5.44)\end{array}$ & 0.007 & 475 & $\begin{array}{c}2.31 \\
(1.31-4.07)\end{array}$ & 0.01 & 248 & $\begin{array}{c}2.30 \\
(1.13-4.68)\end{array}$ & 0.03 \\
\hline \multicolumn{13}{|l|}{ J wave amplitude } \\
\hline $0.1-0.19 \mathrm{mV}(n=409)$ & 342 & $\begin{array}{c}1.79 \\
(1.21-2.65)\end{array}$ & 0.03 & 178 & $\begin{array}{c}1.66 \\
(1.10-2.51)\end{array}$ & 0.04 & 311 & $\begin{array}{c}1.88 \\
(1.26-2.81)\end{array}$ & 0.01 & 143 & $\begin{array}{c}1.68 \\
(1.09-2.59)\end{array}$ & 0.04 \\
\hline$\geq 0.2 \mathrm{mV}(n=227)$ & 203 & $\begin{array}{c}2.87 \\
(1.45-5.68)\end{array}$ & 0.007 & 133 & $\begin{array}{c}3.36 \\
(1.61-7.01)\end{array}$ & 0.003 & 164 & $\begin{array}{c}2.70 \\
(1.36-5.36)\end{array}$ & 0.01 & 108 & $\begin{array}{c}3.33 \\
(1.57-7.06)\end{array}$ & 0.004 \\
\hline \multicolumn{13}{|l|}{ J wave location } \\
\hline $\begin{array}{l}\text { Inferior leads only } \\
(n=374)\end{array}$ & 318 & $\begin{array}{c}1.97 \\
(1.28-3.03)\end{array}$ & 0.02 & 178 & $\begin{array}{c}1.97 \\
(1.23-3.16)\end{array}$ & 0.03 & 273 & $\begin{array}{c}1.96 \\
(1.26-3.05)\end{array}$ & 0.02 & 150 & $\begin{array}{c}2.09 \\
(1.28-3.41)\end{array}$ & 0.02 \\
\hline $\begin{array}{l}\text { Lateral leads only } \\
(n=178)\end{array}$ & 154 & $\begin{array}{c}2.17 \\
(1.03-4.57)\end{array}$ & 0.04 & 91 & $\begin{array}{c}2.29 \\
(1.04-5.04)\end{array}$ & 0.04 & 133 & $\begin{array}{c}2.18 \\
(1.02-4.66)\end{array}$ & 0.04 & 77 & $\begin{array}{c}2.44 \\
(1.08-5.51)\end{array}$ & 0.03 \\
\hline $\begin{array}{l}\text { Both inferior and } \\
\text { lateral leads }(n=84)\end{array}$ & 73 & $\begin{array}{c}2.42 \\
(0.90-6.51)\end{array}$ & 0.12 & 42 & $\begin{array}{c}2.47 \\
(0.87-7.01)\end{array}$ & 0.13 & 70 & $\begin{array}{c}2.67 \\
(0.97-7.35)\end{array}$ & 0.09 & 21 & $\begin{array}{c}1.56 \\
(0.57-4.27)\end{array}$ & 0.34 \\
\hline \multicolumn{13}{|l|}{ Configuration } \\
\hline Notching $(n=199)$ & 175 & $\begin{array}{c}2.48 \\
(1.27-4.84)\end{array}$ & 0.02 & 98 & $\begin{array}{c}2.45 \\
(1.22-4.92)\end{array}$ & 0.03 & 150 & $\begin{array}{c}2.46 \\
(1.25-4.84)\end{array}$ & 0.04 & 101 & $\begin{array}{c}3.23 \\
(1.52-6.86)\end{array}$ & 0.007 \\
\hline Slurring $(n=437)$ & 370 & $\begin{array}{c}1.93 \\
(1.30-2.87)\end{array}$ & 0.01 & 213 & $\begin{array}{c}1.98 \\
(1.28-3.06)\end{array}$ & 0.02 & 325 & $\begin{array}{c}1.96 \\
(1.31-2.93)\end{array}$ & 0.008 & 147 & $\begin{array}{c}1.72 \\
(1.11-2.67)\end{array}$ & 0.04 \\
\hline \multicolumn{13}{|l|}{ ST segment } \\
\hline $\begin{array}{l}\text { Rapidly ascending } \\
(n=112)\end{array}$ & 98 & $\begin{array}{c}2.48 \\
(0.82-7.19)\end{array}$ & 0.11 & 63 & $\begin{array}{c}2.78 \\
(0.90-8.62)\end{array}$ & 0.08 & 77 & $\begin{array}{c}2.21 \\
(0.73-6.67)\end{array}$ & 0.16 & 38 & $\begin{array}{c}2.14 \\
(0.65-7.04)\end{array}$ & 0.21 \\
\hline $\begin{array}{l}\text { Horizontal or descend- } \\
\text { ing }(n=524)\end{array}$ & -447 & $\begin{array}{c}2.01 \\
(1.38-2.93)\end{array}$ & 0.007 & 248 & $\begin{array}{c}1.99 \\
(1.32-3.00)\end{array}$ & 0.009 & 402 & $\begin{array}{c}2.08 \\
(1.41-3.7)\end{array}$ & 0.005 & 210 & $\begin{array}{c}2.12 \\
(1.38-3.56)\end{array}$ & 0.008 \\
\hline
\end{tabular}

*Multivariate logistic regression analysis adjusted for age, sex, body mass index, hypertension, hyperlipidemia, diabetes mellitus and smoking status. ERP indicates early repolarization; and OR, odds ratio.

several conventional risk factors. Among low-risk and intermediate-risk patients, the presence of ERP in addition to traditional risk factors predicts higher rates of obstructive CAD, especially of multi-vessel disease. J-point elevation in inferior leads or lateral leads and a horizontal or descending ST segment appeared to connote higher risk for obstructive CAD.

Recent studies have confirmed smoking, hypertension, diabetes, and dyslipidemia to be risk factors for obstructive CAD. This study is the first to our knowledge to report the association between ERP and coronary stenosis diagnosed by coronary angiography. The risk magnitude appears to be at least as strong as those reported for wellestablished major risk factors. ${ }^{20,21)}$ In real-world clinical settings, low-risk and intermediate-risk patients with CAD might be more easily subjected to misdiagnosis than highrisk patients. In addition, patients with multi-vessel CAD had a greater chance of developing acute myocardial infarction and sudden cardiac death than those with singlevessel CAD, and the early detection of this patient group could be of greater importance. ${ }^{22,23)}$ Therefore, our study could have a potential interesting clinical implication, thanks to the widespread availability and low cost of ECG, to stratify patients with low or intermediate risk into those who need coronary angiography from those who do not.

In agreement with the results of previous studies, the ERP was associated with several demographic and other characteristics, such as male sex, current smoking, lower
BMI, and blood pressure ${ }^{4,24}$. In addition, TC, LDL-C, and TG were lower in subjects with ERP than in those without this abnormality. However, average resting heart rate and age were not systematically different between subjects with ERP and those without ERP. Previous studies showed that the prevalence of ERP in the general population apparently varied between $2 \%$ and $31 \%$ according to the inclusion or exclusion of ST-segment elevation. ${ }^{25,26)}$ However, according to a consensus paper published in 2015, ST-segment elevation is not a required criterion for the diagnosis of ERP. ${ }^{1)}$ Accordingly, our study using the agreed definition found $21.6 \%$ of subjects undergoing coronary angiography manifested end QRS notching or slurring.

The underlying mechanisms involved in the association between ERP and obstructive CAD remain unclear, but several plausible explanations have been suggested. First, myocardial ischemia might reduce inward currents (principally $\mathrm{I}_{\mathrm{Na}}$ and $\mathrm{I}_{\mathrm{Ca}}$ ), which increases outward potassium currents mediated by the $\mathrm{I}_{\mathrm{to}}, \mathrm{I}_{\mathrm{K} \text {-ATP }}$, and $\mathrm{I}_{\mathrm{K} \text {-Ach }}$ channels, especially in the epicardium, resulting in a disproportionate amplification of the repolarizing current in the epicardial myocardium, and thus transmural differences in the early phases (phases 1 and 2) of the cardiac action potential that might be responsible for the $\mathrm{J}$ wave on electrocardiography. ${ }^{27)}$ Second, another possible interpretation for this association may be that J-point elevation on the ECG represented a peri-infarction block, which usually suggests latent CAD. This hypothesis was supported by augmenta- 
tion of the $\mathrm{J}$ wave by rapid pacing in a patient with vasospastic angina. ${ }^{15)}$ Third, of note, in our study, ERP in inferior or lateral leads was associated with stenoses of all 3 main coronary arteries. This indicates that the arterial territory of significant stenosis might not influence the localization of ERP in ECG significantly and a different mechanism other than ischemia or peri-infarction block might be involved. It is possible that the pathogeneses of ERP and CAD might share common factors, such as calcium-sensing receptors (CSR), which have been reported to be involved in the development of vascular calcification and atherosclerosis. ${ }^{28}$ ) In another way, CSR in the endothelial layer of coronary arteries could activate $\mathrm{I}_{\mathrm{KCa}}$ and intensify outward potassium currents, which may cause $\mathrm{J}$ waves on ECG. Given that ERP could increase the risk of sudden cardiac death and that CAD was associated with ERP, we proposed that ERP might lie on the pathway between obstructive CAD and sudden cardiac death for some patients.

The strengths of this study include the strict inclusion criteria, the large number of patients analyzed, and the fact that all subgroup analyses were prespecified a priori. Another strength is that cases of obstructive CAD were detected via coronary angiography, which remains the "gold standard" for the assessment of coronary anatomy. A further strength of this study is the application of a newly agreed definition in the diagnosis of ERP, which might produce repeatable measurements, and greatly reduce between-reader variability and misdiagnosis.

There are several limitations to our study. First, we selected patients who had undergone coronary angiography for various reasons, such as chest pain, pre-operative evaluation, or malignant ventricular arrhythmia, which could have introduced selection bias because some patients with obstructive CAD might be asymptomatic. Second, we could not find the ECG before coronary angiography for most patients; we thus cannot comment on whether ERP is a permanent or transient ECG pattern, or exclude the possibility that some subjects with ERP before admission might exhibit no ERP on ECG prior to coronary angiography. Third, some important confounding factors possibly associated with obstructive CAD, such as diet, physical activity, and socioeconomic factors were not evaluated. Fourth, this study mainly included middle-aged and elderly subjects who underwent coronary angiography, and thus we cannot comment on the implication of ERP for younger subjects, which calls for further external validation of our model in this population group. Fifth, we excluded a small proportion of subjects $(<1 \%)$ for whom J-point amplitude data were missing, however, this might not influence the results significantly given the small sample size excluded. In conclusion, ERP was independently associated with obstructive CAD in patients who underwent coronary angiography, with incremental predictive value to significant coronary stenosis, particularly among subjects with low risk or intermediate risk and those with multi-vessel disease. Further studies, including welldesigned prospective cohort studies and experimental studies, are warranted to confirm our results and to elucidate the specific pathogenic mechanisms.

\section{Disclosures}

Conflicts of interest: None.

\section{References}

1. Macfarlane PW, Antzelevitch C, Haissaguerre M, et al. The early repolarization pattern: A consensus paper. J Am CollCardiol 2015; 66: 470-7.

2. Klatsky AL, Oehm R, Cooper RA, Udaltsova N, Armstrong MA. The early repolarization normal variant electrocardiogram: correlates and consequences. Am J Med 2003; 115: 171-7.

3. Wu SH, Lin XX, Cheng YJ, Qiang CC, Zhang J. Early repolarization pattern and risk for arrhythmia death: a meta-analysis. J Am CollCardiol 2013; 61: 645-50.

4. Tikkanen JT, Anttonen O, Junttila MJ, et al. Long-term outcome associated with early repolarization on electrocardiography. $\mathrm{N}$ Engl J Med 2009; 361: 2529-37.

5. Cheng YJ, Lin XX, Ji CC, et al. Role of early repolarization pattern in increasing risk of death. J Am Heart Assoc 2016; 5: e003375.

6. Haissaguerre M, Derval N, Sacher F, et al. Sudden cardiac arrest associated with early repolarization. N Engl J Med 2008; 358: 2016-23.

7. Cheng YJ, Mei WY, Chen XM, et al. Long-term prognosis associated with early repolarisation pattern in Chinese population with atherosclerotic risk factors. Heart 2017; 103: 910-6.

8. Hwang KW, Nam GB, Han J, et al. Incidence of atrial tachyarrhythmias in patients with early repolarization syndrome. Int Heart J 2017; 58: 43-9.

9. Tikkanen JT, Wichmann V, Junttila MJ, et al. Association of early repolarization and sudden cardiac death during an acute coronary event. CircArrhythmElectrophysiol 2012; 5: 714-8.

10. Naruse Y, Tada H, Harimura Y, et al. Early repolarization increases the occurrence of sustained ventricular tachyarrhythmias and sudden death in the chronic phase of an acute myocardial infarction. CircArrhythmElectrophysiol 2014; 7: 626-32.

11. Cheng YJ, Li ZY, Yao FJ, et al. Early repolarization is associated with a significantly increased risk of ventricular arrhythmias and sudden cardiac death in patients with structural heart diseases. Heart Rhythm 2017; 14: 1157-64.

12. Hippisley-Cox J, Coupland C, Vinogradova Y, et al. Predicting cardiovascular risk in England and Wales: prospective derivation and validation of QRISK2. BMJ 2008; 336: 1475-82.

13. Wilson PW, D'Agostino RB, Levy D, Belanger AM, Silbershatz H, Kannel WB. Prediction of coronary heart disease using risk factor categories. Circulation 1998; 97: 1837-47.

14. Khot UN, Khot MB, Bajzer CT, et al. Prevalence of conventional risk factors in patients with coronary heart disease. JAMA 2003; 290: 898-904

15. Sato A, Watanabe H, Sonoda K, et al. Augmentation of the J wave by rapid pacing in a patient with vasospastic angina. Int $\mathbf{J}$ Cardiol 2014; 172: e111-3.

16. Austen WG, Edwards JE, Frye RL, et al. A reporting system on patients evaluated for coronary artery disease. Report of the Ad Hoc Committee for Grading of Coronary Artery Disease, Council on Cardiovascular Surgery, American Heart Association. Circulation 1975; 51: 5-40.

17. Uppal S, DeCicco AE, Intini A, Josephson RA. Rapid desensitization to overcome contrast allergy prior to urgent coronary angiography. Int Heart J 2018; 59: 622-5.

18. DeLong ER, DeLong DM, Clarke-Pearson DL. Comparing the areas under two or more correlated receiver operating characteristic curves: a nonparametric approach. Biometrics 1988; 44 : 837-45.

19. Pencina MJ, D’Agostino RS, D’Agostino RJ, Vasan RS. Evaluating the added predictive ability of a new marker: from area under the ROC curve to reclassification and beyond. Stat Med 2008; 27: 157-72. 
20. Fihn SD, Blankenship JC, Alexander KP, et al. 2014 ACC/AHA/ AATS/PCNA/SCAI/STS focused update of the guideline for the diagnosis and management of patients with stable ischemic heart disease: a report of the American College of Cardiology/ American Heart Association Task Force on Practice Guidelines, and the American Association for Thoracic Surgery, Preventive Cardiovascular Nurses Association, Society for Cardiovascular Angiography and Interventions, and Society of Thoracic Surgeons. J Am CollCardiol 2014; 64: 1929-49.

21. Naito R, Miyauchi K. Coronary Artery Disease and Type 2 Diabetes Mellitus. Int Heart J 2017; 58: 475-80.

22. Su P, Gu S, Liu Y, et al. Off-Pump Coronary Artery Bypass Grafting with Mini-Sternotomy in the Treatment of TripleVessel Coronary Artery Disease. Int Heart J 2018; 59: 474-81.

23. Hao Z, Xinwei J, Ahmed Z, et al. The outcome of percutaneous coronary intervention for significant atherosclerotic lesions in segment proximal to myocardial bridge at left anterior descend- ing coronary artery. Int Heart J 2018; 59: 467-73.

24. Kimura Y, Yamada M, Hanada K, et al. Relationship between serum eicosapentaenoic acid levels and J-waves in a general population in Japan. Int Heart J 2018; 59: 736-40.

25. Heng SJ, Clark EN, Macfarlane PW. End QRS notching or slurring in the electrocardiogram: influence on the definition of "early repolarization". J Am CollCardiol 2012; 60: 947-8.

26. Haruta D, Matsuo K, Tsuneto A, et al. Incidence and prognostic value of early repolarization pattern in the 12-lead electrocardiogram. Circulation 2011; 123: 2931-7.

27. Shaw RM, Rudy Y. Electrophysiologic effects of acute myocardial ischemia: a theoretical study of altered cell excitability and action potential duration. Cardiovasc Res 1997; 35: 256-72.

28. Alam MU, Kirton JP, Wilkinson FL, et al. Calcification is associated with loss of functional calcium-sensing receptor in vascular smooth muscle cells. Cardiovasc Res 2009; 81: 260-8. 